\title{
Status of Nutrition and Cardiovascular System in Children From the South Moravian Region of the Czech Republic: A Pilot Study
}

\author{
K. LINHARTOVÁ ${ }^{1}$, K. BUDINSKAYA ${ }^{2}$, J. SVAČINOVÁ ${ }^{2}$, V. SVÍZELA ${ }^{2}$, M. PROKES̆ ${ }^{2}$, \\ N. PROKEŠOVÁ-KOSOVÁ ${ }^{2}$ J. NOVÁK ${ }^{2}, \mathrm{Z}$. NOVÁKOVÁ \\ ${ }^{1}$ Department of Public Health, Faculty of Medicine, Masaryk University, Brno, Czech Republic, \\ ${ }^{2}$ Department of Physiology, Faculty of Medicine, Masaryk University, Brno, Czech Republic
}

Received March 31, 2019

Accepted September 4, 2019

\section{Summary}

Nutritional status, its assessment and its influence on numerous diseases is currently still being discussed. The aim of this study was to determine the current state of nutrition by various research methods in school children. Also, to verify the accuracy of body mass index (BMI) determination in school environment and to compare the nutritional status in two different types of school. We used a quantitative questionnaire method in 64 children from schools in the South Moravian Region. We have verified the weight and height measurement in the same group by sophisticated instruments. We have determined the basic parameters of the cardiovascular system (non-invasive continuously blood pressure recording; mutual spectral analysis for estimation of baroreflex sensitivity; applanation tonometry and cardiac polygraphy for arterial stiffness evaluation). The indicative questionnaire method encountered a problem with the weight of almost $40 \%$ of the population approached - both obesity (14.3\%) and malnutrition (25.2\%). Cardiovascular parameters were in physiological range for the given age categories. We found increased values in BMI, \% of body fat and heart rate in children from countryside type of school, respecttively. We concluded that obesity/malnutrition are both common phenomena in the children population in the Czech Republic.

\section{Key words}

Childhood obesity • Body mass index • Cardiovascular system • Cardio-ankle vascular index (CAVI) • Baroreflex Sensitivity

\section{Corresponding author}

Z. Nováková, Department of Physiology, Faculty of Medicine, Masaryk University, Kamenice 5, 62500 Brno, Czech Republic. E-mail: znovak@med.muni.cz

\section{Introduction}

Obesity and overweight represents an important public health problem in the developed countries all over the world (Kumar and Kelly 2017). Prevalence of obesity is increasing worldwide and the increase in obesity prevalence in younger age groups is alarming. The prevalence of childhood obesity was $4.2 \%$ in 1990 , increased to $6.7 \%$ in 2010 and is estimated to reach $9.1 \%$ in 2020 (de Onis et al. 2010). In 2014, there were 600 million obese people worldwide, of whom 41 million were obese children aged under five years (Hayashi et al. 2018). The Czech Republic has its own unique anthropological analyses from years 1951, 1981, 1991, and 2001. These analyses are in good accordance with the WHO data showing increase in prevalence of both overweight and obesity also in the Czech children's population (Vignerova et al. 2008, Kratenova et al. 2017).

The management of childhood obesity requires interdisciplinary approach and moreover, interaction with family and schools is essential as obesity development is also affected by the eating patterns observed in the family and by socio-economic status (Bodzsar and Zsakai 2014). The main complications associated with childhood obesity are its persistence into adulthood (Parson et al. 1999) and the development of so called "adult diseases", such as hypertension, type 2 diabetes mellitus or dyslipidemia, also in pediatric population (Kumar and Kelly 2017). Cardiovascular diseases still represent one of the leading causes of death in the developed countries and healthy life-style (including regularly performed 
physical activity and healthy eating) shall be encouraged and promoted already in children to avoid these diseases development in future.

Within our pilot study, we attempted to characterize the nutritional status and cardiovascular system function in school children from two types of school (city and countryside) from the South Moravian region of the Czech Republic.

\section{Methods}

The study was approved by Ethical committee of Faculty of Medicine, Masaryk University Brno, the Czech Republic. It was conducted in accordance with the principles stated in the Declaration of Helsinki. All respondents (pupils under 18 years of age) and their parents were informed about the aim and purposes of the study and they signed the informed consent that was archived.

\section{Questionnaires}

After obtaining the informed consent, children were asked to fill in the questionnaire with the help of the class teacher. The questionnaire focused on the demographic data (age, gender, body weight, body height, and weight status of parents and siblings), daily physical activity (mileage per day, regular exercise) and inactivity (sitting position with digital media use, including watching television, working with personal computer or mobile phone). Direct measurements of anthropometric and cardiovascular parameters (as described further) were performed at the same day when questionnaire was filled in.

\section{Anthropometry}

Body weight in kilograms $(\mathrm{kg})$ and the percentage of body fat (\%) was determined using the personal weight TANITA (bioimpedance method). Body height was assessed using TANITA HR-001 portable altimeter. Caliper (BEST K-501; official anthropometric gauge) was used to measure two skin folds (over the triceps and under the scapula on non-dominant upper limb) independently by two trained persons. Waist-to-hip ratio was measured by certified centimeter.

Based on the obtained results of weight and height, BMI was calculated by dividing the weight in kilos by the square of height in meters. The classification of respondents into weight categories (severe malnutrition, underweight, ideal weight, overweight, obesity) was carried out with respect to the developmental fact of the two basic components from which BMI is determined, taking into account the percentile graphs, according to Centers for Disease Control and Prevention USA (Ogden et al. 2002).

\section{Cardiovascular function assessment}

Non-invasive continuous blood pressure measurement by photo-plethysmography method according to Penaz (Finometer, FMS, Netherlands) was used. Two measurements were performed: $5 \mathrm{~min}$ recording under resting conditions (i.e. sitting) and $5 \mathrm{~min}$ recording of standing to provoke autonomous nervous system regulation (i.e. orthostatic challenge; Ondrusova et al. 2017). Children breathed according to the metronome at the frequency of $0.33 \mathrm{~Hz}$ ( 20 breaths $/ \mathrm{min}$ ) in both phases. Paced breathing eliminates influence of respiratory sinus arrhythmia to the heart rate variability on low frequency band (0.14-0.15 Hz, Honzikova et al. 1995, Porta et al. 2012).

Sequences of systolic blood pressure (SBP), diastolic blood pressure (DBP) and inter-beat intervals (IBI; defined as a time interval between two neighboring local blood pressure minima corresponding to diastolic blood pressure) were detected beat-to-beat from the $5 \mathrm{~min}$ long continuous blood pressure signals. Pulse pressure (PP) was defined as difference between consecutive samples of SBP and DBP. Baroreflex sensitivity (BRS; IBI change caused by SBP change by $1 \mathrm{~mm} \mathrm{Hg}$ ) as a gain of transfer function from IBI to SBP was computed using cross-spectral analysis (Svacinova et al. 2013, Honzikova and Fiser 2009, Zavodna et al. 2006). BRS was evaluated as a mean gain in the low frequency band (0.04-0.15 Hz). Variability of heart rate reflecting respiratory sinus arrhythmia (RSA) was computed as a mean power spectral density of IBI in the high frequency band (HF; $0.15-0.5 \mathrm{~Hz}$ ). RSA is a parameter of parasympathetic activity (Eckberg 1983, Malliani 1999).

From the obtained sequences, mean values and standard deviations were computed (meanIBI, sdIBI, meanSBP, sdSBP, meanDBP, sdDBP, meanPP, sdPP). Standard deviation is a simple parameter of overall cardiovascular signal variability. All parameters were calculated for both phases of measurement, sitting and standing.

\section{Vascular system data collection}

Cardio-ankle vascular index (CAVI) was determined using a VaSera device (Fukuda Denshi, 
Tokyo, Japan). The ECG, phonocardiography, pressures and waveforms of brachial and ankle arteries were measured. CAVI values were automatically calculated by the VaSera. ABI is defined as the ratio of the higher of the systolic blood pressures of the 2 ankle arteries of that limb (either the dorsalis pedis or the tibial artery) and the higher of the 2 systolic blood pressures of the upper limbs (Shirai et al. 2006).

Pulse wave velocity (PWV) was measured by applanation tonometry with Sphygmocor (AtCor Medical, Australia). Measurement was performed on the dominant hand on radial and carotid arteries. PWV was calculated dividing distance between carotid and radial arteries by transition time (difference between time from R-wave on ECG to forward wave on radial artery and time from R-wave on ECG to forward ware on carotid artery). All measurements were corrected by oscillometric blood pressure measurement on the brachial artery (Omron HEM, 907) on the same side.

The following parameters were calculated from peripheral and central curves: SBPact, DBPact ( $\mathrm{mm} \mathrm{Hg}$ ), augmentation pressure (AP; $\mathrm{mm} \mathrm{Hg}$ ), augmentation index (AI; \%). The both parameters are influenced by heart rate and thus, to minimize this influence, values of AP and AI were standardized to a heart rate $75 / \mathrm{min}$ and pulse height - APHR75 (Korpas et al. 2009, Budinskaya et al. 2017).

\section{Results}

\section{Questionnaires}

The questionnaire was completed by sixty-four children (13-15 years, mean age: 13.9 \pm 0.71 years;
34 boys, 30 girls) from different types of schools in the South Moravia Region of the Czech Republic.

Concerning the self-reported anthropometric parameters, thirty-nine children $(60.9 \%)$ had the ideal weight, fourteen children presented with underweight $(22.0 \%)$ and two with severe malnutrition (3.2\%). Overweight/obesity was observed in $6(9.5 \%) / 3(4.8 \%)$ of children. There was a statistically significant correlation between these values of self-reported BMI using the questionnaire and the BMI measured by anthropometric instruments by a trained members of our team (Spearman's correlation coefficient; $r=0.8505$, $\mathrm{P} \leq 0.0001$ ), which indicates that self-reported BMI in these population is satisfactory precise.

Exercise activity: For the whole group, mean number of kilometers per day (mileage) was $3.88 \mathrm{~km} /$ day (range $1-10 \mathrm{~km}$ ) and the time spent sitting using digital media was $5.24 \mathrm{~h}$ /day (range 1-10 h). Twenty eight pupils $(43.8 \%)$ fulfilled the standard for a healthy lifestyle defined as $4 \mathrm{~km}$ or more per day. Five to six hours are spent daily in school during the weekdays. From the whole cohort, $65.1 \%$ of children is dedicated to do some sports.

\section{Anthropometry}

Table 1 shows the results of nutritional status measurements, which expresses the basic characteristics of study group. When comparing girls and boys, there were no significant differences in body weight, BMI, waist and hip circumference and skin fold over the triceps. Both genders differed significantly in body height, \% of body fat and waist-to-hip ratio $(\mathrm{P}<0.001)$.

Table 1. Evaluation of nutritional state - basic characteristics of data set.

\begin{tabular}{lcccc}
\hline Parameters & Whole group & Boys & Girls & P value \\
\hline Number of subjects & 64 & 34 & 30 & $\mathrm{NS}$ \\
Weight $(\mathrm{kg})$ & $55.6(49.0-64.7)$ & $58.6(52.3-64.7)$ & $53.3(48.5-64.5)$ & $<0.001$ \\
Height $(\mathrm{m})$ & $166.0(161.0-173.0)$ & $171.5(166.0-174.0)$ & $162.0(159.0-164.0)$ & $\mathrm{NS}$ \\
BMI $\left(\mathrm{kg} / \mathrm{m}^{2}\right)$ & $20.0(18.7-22.8)$ & $19.8(18.9-22.0)$ & $20.9(18.3-22.8)$ & $<0.001$ \\
Fat $(\%)$ & $22.9(17.5-26.9)$ & $17.9(15.3-21.9)$ & $25.9(22.9-28.6)$ & $\mathrm{NS}$ \\
Waist $(\mathrm{cm})$ & $68.0(63.0-73.0)$ & $69.5(65.0-74.0)$ & $65.5(62.0-72.0)$ & $\mathrm{NS}$ \\
Hip $(\mathrm{cm})$ & $89.5(83.5-95.0)$ & $90.0(83.0-94.0)$ & $88.5(85.0-98.0)$ & $<0.001$ \\
Waist/Hip & $0.76(0.72-0.81)$ & $0.79(0.75-0.85)$ & $0.73(0.71-0.77)$ & $\mathrm{NS}$ \\
Skin fold triceps $(\mathrm{cm})$ & $0.8(0.5-1.05)$ & $0.8(0.4-1.0)$ & $0.8(0.5-1.1)$ & $<0.05$ \\
Skin fold scapula $(\mathrm{cm})$ & $0.75(0.50-1.00)$ & $0.65(0.50-0.80)$ & $0.90(0.60-1.00)$ &
\end{tabular}

Parameters are expressed as median (lower quartile - upper quartile). BMI - body mass index in $\mathrm{kg} / \mathrm{m}^{2}$; P value: statistical evaluation differences between boys versus girls, Mann Whitney test, NS - non-significant. 
Cardiovascular function assessment

Cardiovascular parameters from 5-minute-long continuous beat-to-beat measurements of blood pressures are shown in Table 2. There were no statistically significant differences between boys and girls. We found statistically significant decrease of mean IBI, mean PP and BRS (sitting vs. standing: 682 vs. $596 \mathrm{~ms}, \mathrm{P}<0.001$; 39 vs. $35 \mathrm{~mm} \mathrm{Hg}, \mathrm{P}<0.001$; 9.2 vs. $5.9 \mathrm{~ms} / \mathrm{mm} \mathrm{Hg}$, $\mathrm{P}<0.001)$ and increase of mean HR and mean DBP (1474 vs. $1688 \mathrm{mHz}, \quad \mathrm{P}<0.001 ; 73$ vs. $78 \mathrm{~mm} \mathrm{Hg}, \quad \mathrm{P}<0.01$ ) between sitting and resting position.

There were no statistically significant differences between boys and girls with exception of
SBPact (boys vs. girls: 116 vs. $106 \mathrm{~mm} \mathrm{Hg}, \mathrm{P} \leq 0.01$ ) in all other vascular parameters (as shown in Table 3 ).

Table 4 shows statistically significant correlations among BMI, \% of body fat, waist-to-hip ratio and some of the cardiovascular parameters calculated using Spearman's coefficient. The strongest correlation was observed between peripherally and centrally measured SBP with BMI and waist-to-hip ratio $(\mathrm{P}<0.001)$.

The values of the cardiovascular parameters of the subgroup of only obese children compared to the subgroup of only malnourished children aged 13-15 years showed no statistically significant differences.

Table 2. Cardiovascular parameters during sitting and standing position (orthostatic challenge).

\begin{tabular}{|c|c|c|c|}
\hline Parameters & Sitting position & Standing position & $P$ value \\
\hline $\operatorname{IBI}(\mathrm{ms})$ & $682(629.0-785.8)$ & $596(561.8-636.1)$ & $<0.001$ \\
\hline$s d I B I(m s)$ & $57.3(46.4-80.952)$ & $46.0(37.3-54.2)$ & $<0.001$ \\
\hline$H R(m H z)$ & $1473(1279.8-1597.7)$ & $1688(1587.6-1791.1)$ & $<0.001$ \\
\hline$s d H R(m H z)$ & $113.5(98.8-134.2)$ & $118.0(106.5-137.1)$ & NS \\
\hline $\mathrm{SBP}(\mathrm{mm} \mathrm{Hg})$ & $114.3(101.3-122.3)$ & $111.5(101.8-123.2)$ & NS \\
\hline$s d S B P(m m ~ H g)$ & $6.4(5.3-8.1)$ & $7.2(5.9-8.3)$ & $<0.05$ \\
\hline$D B P(m m ~ H g)$ & $73.1(65.9-81.3)$ & $77.9(70.8-83.9)$ & $<0.01$ \\
\hline$s d D B P(m m ~ H g)$ & $4.3(3.6-5.4)$ & $5.2(4.4-5.8)$ & $<0.001$ \\
\hline$P P(m m H g)$ & $39.4(32.3-45.5)$ & $34.7(28.5-40.8)$ & $<0.001$ \\
\hline$s d P P(m m ~ H g)$ & $4.6(3.9-5.2)$ & $4.2(3.6-5.3)$ & NS \\
\hline LFgain $=B R S(\mathrm{~ms} / \mathrm{mm} \mathrm{Hg})$ & $9.2(6.4-11.8)$ & $5.9(4.3-8.5)$ & $<0.001$ \\
\hline
\end{tabular}

Parameters are expressed as median (lower quartile - upper quartile). Parameters from 5-min blood pressure record by Penaz method: IBI (mean inter-beat interval) \pm standard deviation (sdIBI), HR (mean heart rate in $\mathrm{mHz}$ ) \pm standard deviation (sdHR), SBP-DBP (mean systolic and diastolic blood pressures) \pm standard deviation (sdSBP, sdDBP), PP (mean pulse pressure) \pm standard deviation (sdPP), LF gain=baroreflex sensitivity (BRS).

Table 3. Vascular parameters data set.

\begin{tabular}{lccc}
\hline Parameters & Whole group & Boys & Girls \\
\hline SBPact $(\mathrm{mm} \mathrm{Hg})$ & $108.0(101.0-116.0)$ & $116.0(107.0-121.0)$ & $106.0 * *(98.0-108.0)$ \\
DBPact $(\mathrm{mm} \mathrm{Hg})$ & $61.0(54.0-67.0)$ & $61.0(54.0-65.0)$ & $64.0(55.0-75.0)$ \\
$M A P(\mathrm{~mm} \mathrm{Hg})$ & $75.0(69.0-81.0)$ & $77.0(70.0-81.0)$ & $76.0(69.0-82.0)$ \\
$A P H R 75(\mathrm{~mm} \mathrm{Hg})$ & $-1.0(-3.0-+1.0)$ & $-1.0(-3.0-+1.0)$ & $0.0(-2.0-+2.0)$ \\
$P W V(\mathrm{~m} / \mathrm{s})$ & $6.8(5.9-7.8)$ & $7.0(5.9-7.7)$ & $6.9(5.8-8.3)$ \\
$C A V I R$ & $4.7(4.3-5.2)$ & $4.6(4.3-5.2)$ & $4.7(4.1-5.0)$ \\
CAVI L & $4.8(4.3-5.2)$ & $4.9(4.3-5.2)$ & $4.8(4.2-5.2)$ \\
$A B I R$ & $0.98(0.86-1.04)$ & $0.99(0.87-1.06)$ & $0.87(0.85-0.98)$ \\
$A B I L$ & $0.95(0.88-1.02)$ & $0.98(0.90-1.03)$ & $0.88(0.85-0.93)$ \\
\hline
\end{tabular}

Parameters are expressed as median (lower quartile - upper quartile). SBPact, DBPact - actually measurement blood pressure by Omron device; parameters measured by SphygmoCor: MAP (mean arterial pressure), AP HR75 (augmentation pressure recalculated on heart rate=75 bpm; parameters measured by VaSera device: CAVI R/L (cardio-ankle vascular index on right/left side of body), ABI R/L (ankle-brachial index on right/left side of the body) $* * \mathrm{P}<0.01 ;$ Mann-Whitney test. 
Table 4. Correlation between parameters for evaluation of nutritional state and cardiovascular parameters in the whole group of children.

\begin{tabular}{lcc}
\hline Parameters & $\mathbf{r}$ & $\mathbf{P}$ \\
\hline BMI-CAVIR & -0.3006 & 0.021 \\
BMI-CAVI & -0.3089 & 0.017 \\
BMI-SBPact & 0.3895 & 0.003 \\
BMI-SBPcent & 0.4191 & 0.001 \\
BMI-DBPcent & 0.2730 & 0.042 \\
Waist/hip -SBPact & 0.4185 & 0.001 \\
Waist/hip -SBPcent & 0.3312 & 0.012 \\
\%fat - ABI R & -0.3178 & 0.023 \\
\%fat - ABI L & -0.3455 & 0.013 \\
\%fat - DBPact & 0.2737 & 0.041 \\
\hline
\end{tabular}

$\mathrm{r}$ - Spearman's correlation coefficient; P - P value (statistical significance); BMI - body mass index $\left(\mathrm{kg} / \mathrm{m}^{2}\right)$, CAVI R/L - cardio-ankle vascular index on right/left side of body; ABI R/L - ankle-brachial index on right/left side of body; SBPact/DBPact - systolic/diastolic blood pressure measure by Omron device immediately after pulse wave record was done; SBPcent/DBPcent - systolic and diastolic blood pressures modified by SphygmoCor device on central aortic pulse wave.

Comparison between city and countryside children

We further divided our respondents into two subgroups according to the type of school they attendedcity or countryside - as one of the examples of their socio-economic status.

The Fig. 1 shows the differences between the statistically significant parameters between city vs. countryside: BMI (19.8 vs. $\left.22.3 \mathrm{~kg} / \mathrm{m}^{2} ; \mathrm{P}<0.05\right), \%$ of body fat (20 vs. $27.3 \%$; $<<0.05)$, heart rate $(72$ vs. 87 bpm; $\mathrm{P}<0.01$ ), respiratory sinus arrhythmia (RSA; RSA; 113 vs. $\left.55.9 \mathrm{~ms}^{2} ; \mathrm{P}<0.05\right)$.
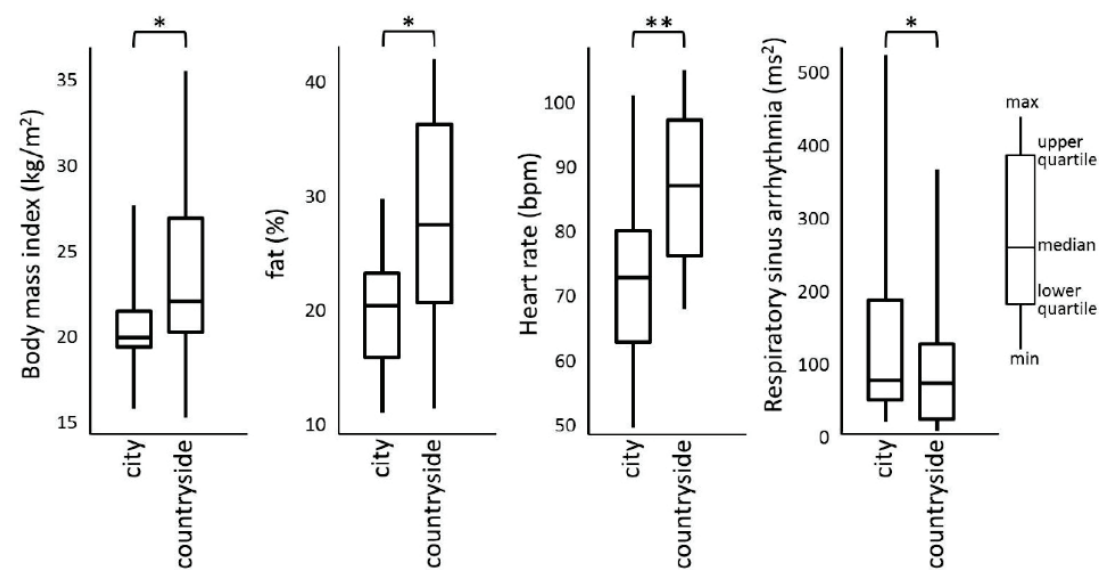

Fig. 1. Differences of nutritional and cardiovascular parameters between city and countryside schools.

\section{Discussion}

In our pilot study, we characterize nutritional status and cardiovascular system function in the group of 64 school children from the two types of schools (city and countryside) from the South Moravian region of the Czech Republic. Using BMI, as an accepted parameter for assessing nutritional status, $25.2 \%$ of our respondents were classified as underweight or malnutrition, $14.3 \%$ as overweight or obesity. Similar results are also described in other similar studies (Mikolajczyk and Richter 2008, Ticha et al. 2018). However, the values for height and weight expressed by BMI do not provide information on percentages and fat distribution in the body (Freedmann et al. 2009). Moreover, especially in the children population, differences in fat percentage between girls and boys need to be assessed as they are related to gradually establishing physiological changes in fat 
storage associated with the onset of puberty (Kaplowitz 2008). With onset of puberty, both estrogens and testosterone stimulate differentiation of fat tissue. Testosterone promotes proliferation in visceral fat, whereas estrogen (hypothetically oestradiol) support proliferation of pre-adipocytes to adipocytes in subcutaneous fat (Matosyan et al. 2015). These physiological hormonal changes explain differences observed between the groups of boys and girls. Overall we can say that boys were taller, presented with lower $\%$ of body fat and with higher waist-to-hip ratio.

Function of the cardiovascular system for the purposes of our study was expressed as heart rate, blood pressures and their variability at resting (sitting) position and standing position. Values of heart rate and blood pressure in the sitting position were fluctuating around the physiological age-dependent values. No significant differences between boys and girls were observed, although girls were expected to present with lower blood pressure than boys (due to the hormonal differences caused by the onset of puberty). It may be hypothesized that anthropometric changes precede changes in the cardiovascular system and thus the blood pressure and heart rate in girls are still comparable to the boys.

It is commonly known that in adult population premenopausal women have lower value of blood pressure than men. This difference is again given by different effects of sex hormones. In girls, with onset puberty the level of estrogen (oestradiol) increases. The oestradiol influence is very wide from local level to nervous regulation. Oestradiol is vasodilator and its effect is mediated through the estrogen receptors (ER) $\alpha$ and $\beta$. Binding of oestradiol to ER $\alpha$ and ER $\beta$ upregulates nitric oxide (NO) synthase and vasodilation occurs (Gou et al. 2005). Both androgens and estrogens extremely influence the renin-angiotensin-aldosterone system (RAAS), however their effects are opposite. Down regulation of angiotensin-converting enzyme (ACE) and angiotensin I (ATI) receptors attenuates the synthesis of Angiotensin II. Protective effect of estrogens against aldosteroneinduced hypertension has been shown in animal experiment. The androgens promote the opposite effect: activation of RAAS through increasing sodium reabsorption in proximal tubule and synthesis of angiotensinogen (Ji et al. 2008).

Baroreflex sensitivity values were within the physiological range (Zavodna et al. 2006) for both groups.

Statistically significant changes in HR, SBP,
DBP, PP, and BRS during provocative maneuver of orthostatic type (sitting-standing) showed good baroreflex regulation through the autonomous nervous system in all the components (Javorka el al. 2010). The observed changes are physiological, i.e. increase in blood pressure and heart rate in response to orthostasis.

Pulse wave velocity is an important parameter for evaluation of arterial stiffness in adults. It is less common to use this standardized method in children, but the growing interest of pediatricians and pediatric cardiologists is observed. The disadvantage of wider employment was the missing age-dependence reference values, which is however already available (Fischer et al. 2012). PWV results of our study are slightly higher than the reference values, but our method reflects the PWV measurement in peripheral arteries (carotid and radial arteries; Budinskaya et al. 2017).

Cardio-ankle and ankle-brachial indexes are relatively new indices for arterial stiffness evaluation reflecting atherosclerosis in large arteries (aorta, femoral artery, tibial artery; Shirai et al. 2006). The research team from Slovakia used these indices for the group of children and adolescents to estimate the risk of cardiovascular diseases in childhood and thus to set important agedependent reference values. Our results correspond to these values for a healthy children population (Jurko et al. 2018).

Inverse relationship between CAVI and BMI was shown by team of authors from the USA (Phillip et al. 2015) similarly to our results (as shown in Table 4).

Interesting results were provided by comparing the children from the city and countryside. Differences in basic parameters evaluating nutritional status - BMI, amount of fat (\%) and differences in heart rate and RSA presence were observed. Despite our results are limited due to a rather small number of respondents, they are in correlation with global studies where the trend for higher BMI in rural settlements in adults was recorded as a result of reduced physical activity in these areas (Bixby et al. 2019). Increased heart rate, increased \% of body fat and reduced RSA (as parasympathetic activity indicator; Mestanik et al. 2019) are interlocking effects of enhancing the activity of the sympathetic part of the autonomous nervous system and its impact on cardiovascular regulation. We can hypothesize that these results reflect various differences between the rural and city areas. Increase in BMI and \% of body fat may be influenced by different eating habits and also by different access to food supplies - i.e. families in the cities are 
buying food in supermarkets, while families in the countryside prefer food directly from the farmers. Also, these differences may result from different lifestyle as city children have availability for more leisure activities, including various sports activities and especially in the girls group, city girls are known to look more "trendy". However, these speculations should be confirmed by expanding our study cohort and by expanding the spectrum of questionnaires focusing on the socioeconomic status.

\section{Conclusions}

Obesity/overweight and malnutrition are both common phenomena in the children population. Practical outcome of this study is a good correlation between selfreported BMI (calculated from the children referred data) and the BMI obtained by objective measurements by trained professional. This fact may play an important role in screening and prevention of nutritional disorders in children suggesting the important role of family-schoolphysician cooperation. We can also recommend the bioimpedance method measurement of \% of body fat as a refining parameter for assessing the nutritional status of school children.
The state of the cardiovascular system and its regulation corresponds to the physiological range for the corresponding age groups. It may be interesting to measure all these parameters in the future to identify when the hormonal differences will start taking place.

The prevalence of inactivity due to seating in digital media as well as the percentage of overweight or obesity and malnutrition in the populations of school children have become a challenge for the future to improve these problems by using prevention programs.

In general, our study shall be further expanded to strengthen the statistical power of our results.

\section{Conflict of Interest}

There is no conflict of interest.

\section{Acknowledgements}

This study was supported by grant project MUNI/A/1255/2018. The authors thank Professor Petr Dobšák from the Department of Sports Medicine and Rehabilitation, St Anne's Faculty Hospital and Faculty of Medicine, Masaryk University, Brno, Czech Republic for the kind loan of the VaSera instrument (Fukushi Densa, Japan) for measuring CAVI and ABI parameters.

\section{References}

BIXBY H, BENTHAM J, ZHOU B, Di CESARE M, PACIOREK CJ, BENNETT JE, TADDEI C, STEVENS GA, ET AL.: Rising rural body-mass index is the main driver of the global obesity epidemic in adults. Nature 569: 260-264, 2019.

BODZSAR EB, ZSAKAI A: Recent trends in childhood obesity and overweight in the transition countries of Eastern and Central Europe. Ann Hum Biol 41: 263-270, 2014.

BUDINSKAYA K, PUCHNEROVA V, SVACINOVA J, NOVAK J, HRSTKOVA H, NOVAKOVA M, PEKAROVA A, PEKAR M, NOVAKOVA Z: Non-invasive assessment of vascular system function and damage induced by anthracycline treatment in the pediatric cancer survivors. Physiol Res 66 (Suppl 4): S553-S560, 2017.

DE ONIS M, BLÖSSNER M, BORGHI E: Global prevalence and trends of overweight and obesity among preschool children. Am J Clin Nutr 92: 1257-1264, 2010.

ECKBERG D: Human sinus arrhythmia as an index of vagal cardiac outflow. J Appl Physiol Respir Environ Exerc Physiol 54: 961-966, 1983.

FISCHER DC, SCHREIVER C, HEIMHALT M, NOERENBERG A, HAFFNER D: Pediatric reference values of carotid-femoral pulse wave velocity determined with an oscillometric device. J Hypertens 30: 2159-2167, 2012.

FREEDMAN D, SHERRY B: The validity of BMI as an indicator of body fatness and risk among children. Pediatrics 124: S23-S34, 2009.

GOU X, RAZANDI M, PEDRAM A, KASSAB G, LEVIN ER: Estrogen induces vascular wall dilation mediation through kinase signaling to nitric oxide and estrogen receptors A and B. J Biol Chem 280: 19704-19710, 2005. 
HAYASHI C, KRASEVEC J, KUMAPLEY R, MEHRA V, BORGHI E, FLORES-URRUTIA MC, DOMIQUEZ E, DE ONIS M, PRYDZ EB, SERAJUDDIN U: Levels and trends in child malnutrition: key findings of the 2018. Edition of the Joint Child Malnutrition Estimates. Geneva: World Health Organization; 2018 License: CC BY-NC-SA 3.0 IGO.

HONZIKOVA N, PENAZ J, FISER B, HONZIK J: The relationship between the spontaneous fluctuation in circulation and depth and rate of respiration. Homeost Health Dis 36: 165-169, 1995.

HONZIKOVA N, FISER B: Baroreflex sensitivity and essential hypertension in adolescents. Physiol Res 58: 605-612, 2009.

JAVORKA M, TONHAJZEROVA I, TURIANIKOVA Z, JAVORKA K, HONZIKOVA N, BAUMERT M: Cardiovascular Signals in Diabetes Mellitus: a New Tool to Detect Autonomic Neuropathy. Nova Science Publishers, Inc., New York, 2010, 96 p.

JI H, MENINI S, ZHENG W, PESCE C, WU X, SANDBERG K: Role of angiotensin-converting enzyme 2 and angiotensin (1-7) in 17 beta-oestradiol regulation of renal pathology in renal wrap hypertension in rats. Exp Physiol 93: 648-657, 2008.

JURKO T, MESTANIK M, JURKO A JR, SPRONCK B, AVOLIO A, MESTANIKOVA A, SEKANINOVA N, TONHAJZEROVA I: Pediatric reference values for arterial stiffness parameters cardio-ankle vascular index and CAVI (0). J Am Soc Hypertens 12: e35-e43, 2018.

KAPLOWITZ PB: Link between body fat and the timing of puberty. Pediatrics 121 (Suppl 3): S208-S217, 2008.

KORPAS D, HALEK J, DOLEZAL L: Parameters describing the pulse wave. Physiol Res 58: 473-479, 2009.

KRATENOVA J, ZEJGLICOVA K, MALY M, PUKLOVA V: Results of the study "Children's Health 2016" - Expert Report for 2016 [online]. 2017. B.m.: National Institute of Public Health Prague. Available from: http://www.szu.cz/uploads/documents/chzp/odborne_zpravy/OZ_16/Zdravotni_stav_2016.pdf.

KUMAR S, KELLY AS: Review of childhood obesity: from epidemiology, etiology, and comorbidities to clinical assessment and treatment. Mayo Clin Proc 92: 251-265, 2017.

MALLIANI A: The pattern of sympathovagal balance explored in the frequency domain. Physiology 14: 111-117, 1999.

MATOSYAN KA, ORANSKAYA AN, PUSTOVALOV DA, CHEREPKOVA EV, SKOTNIKOVA UV, BURDYUKOVA EV, ANISHCHENKO AP, GUREVICH KG, KHANFERYAN RA: Adipose tissue composition in puberty and postpuberty according to age, sex (gender), physical activity and alimentary behavior. (Article in Russian) Vopr Pitan 84: 88-94, 2015.

MESTANIK M, MESTANIKOVA A, LANGER P, GRENDAR M, JURKO A JR, SEKANINOVA N, VISNOVCOVA N, TONHAJZEROVA I: Respiratory sinus arrhythmia - testing the method of choice for evaluation of cardiovagal regulation. Respir Physiol Neurobiol 259: 86-92, 2019.

MIKOLAJCZYK RT, RICHTER M: Asociations of behavioural, psychosocial and socioeconomic factors with overand underweight among German adolescents. Int J Public Health 53: 214-220, 2008.

OGDEN CL, KUCZMARSKI RJ, FLEGAL KM, MEI Z, GUO S, WEI R, GRUMMER-STRAWN LM, CURTIN LR, ROCHE AF, JOHNSON CL: Centers for Disease Control and Prevention 2000 Growth Charts for the United States: Improvements to the 1977 National Center for Health Statistics Version. Pediatrics 109: 45-60, 2002.

ONDRUSOVA K, SVACINOVA J, JAVORKA M, NOVAK J, NOVAKOVA M, NOVAKOVA Z: Impaired baroreflex function during orthostatic challenge in patients after spinal cord injury. J Neurotrauma 34: 3381-3387, 2017.

PARSONS TJ, POWER C, LOGAN S, SUMMERBELL CD: Childhood predictors of adult obesity: a systematic review. Int J Obes Relat Metab Disord 23 (Suppl 8): S1-S107, 1999.

PHILIP R, ALPERT BS, SCHWINGSHACKI A, HUANG X, BLAKELY D, ROVNAGHI CR, TRAN QT, VELASQUEZ A, AREVALO A, ANAND KJS: Inverse relationship between cardio-ankle vascular index and body mass index in healthy children. $J$ Pediatr 167: 361e1-365e1, 2015.

PORTA A, BASSANI T, BARI V, PINNA GD, MAESTRI R, GUZZETTI S: Accounting for respiration is necessary to reliably infer granger causality from cardiovascular variability series. IEEE Trans Biomed Eng 59: 832-841, 2012. 
SHIRAI K, UTINO J, OTSUKA K, TAKATA M: A novel blood pressure-independent arterial wall stiffness parameter; Cardio-ankle vascular index (CAVI). J Atheroscler Thromb 13: 101-107, 2006.

SVACINOVA J, HONZIKOVA N, KRTICKA A, TONHAJZEROVA I, JAVORKA K, JAVORKA M: Diagnostic significance of a mild decrease of baroreflex sensitivity with respect to heart rate in type 1 diabetes mellitus. Physiol Res 62: 605-613, 2013.

TICHA L, REGECOVA V, SEBEKOVA K, SEDLAKOVA D, HAMADE J, PODRACKA L: Prevalence of overweight/obesity among 7-year-old children-WHO Childhood Obesity Surveillance Iniciative in Slovakia, trends and differences between selected European countries. Eur J Pediatr 177: 945-953, 2018.

VIGNEROVA J, HUMENIKOVA L, PAULOVA M, RIEDLOVA J: Prevalence of overweight, obesity and low weight in the Czech child population up to 18 years of age in the last 50 years. J Public Health 16: 413-420, 2008.

ZAVODNA E, HONZIKOVA N, HRSTKOVA H, NOVAKOVA Z, MOUDR J, JIRA M, FISER B: Can we detect the development of baroreflex sensitivity in humans between 11 and 20 years of age? Can J Physiol Pharmacol 84: 1275-1283, 2006. 